\title{
Getting Granular on Twitter: Tweets from a Conference and Their Limited Usefulness for Non-participants
}

\author{
Martin Ebner ${ }^{1}$, Herbert Mühlburger ${ }^{1}$, Sandra Schaffert ${ }^{2}$, Mandy Schiefner ${ }^{3}$, \\ Wolfgang Reinhardt ${ }^{4}$, and Steve Wheeler ${ }^{5}$ \\ ${ }^{1}$ Social Learning, Computer and Information Services, \\ Graz University of Technology, Graz, Austria \\ \{martin. ebner, muehlburger\} @tugraz . at \\ ${ }^{2}$ Salzburg Research Forschungsgesellschaft, Salzburg, Austria \\ sandra.schaffertesalzburgresearch.at \\ ${ }^{3}$ Center for University Teaching and Learning, University of Zurich, \\ Zurich, Switzerland \\ mandy.schiefner@access.uzh.ch \\ ${ }^{4}$ Computer Science Education Group, University of Paderborn \\ Paderborn, Germany \\ wolle@upb. de \\ ${ }^{5}$ University of Plymouth, Plymouth, United Kingdom \\ s.wheeler@plymouth.ac.uk
}

\begin{abstract}
The use of microblogging applications (especially Twitter) is becoming increasingly commonplace in a variety of settings. Today, active conference participants can post messages on microblogging platforms to exchange information quickly and in real-time. Recent research work was based on quantitative analyses in terms of the number of tweets or active Twitter users within a specific time period. In this paper, we examine the content of the contributions and aim to analyze how useful posts are for the "listening" Internet auditorium. It can be shown that only a few microblogs are of interest for non-participants of the specific event and that meaningful usage of a microblogging application requires greater care than previously anticipated.
\end{abstract}

Keywords: Twitter, microblogging, conference, analysis.

\section{Introduction: Usage of Twitter at Conferences}

Twitter is the most popular public microblogging system. After a period of testing this form of communication and interaction in science [1] and e-learning [2,3,4], microblogging has finally caught up with the scientific community: Some early adopters use it to share short notices about their work or to comment on the work of others, they use it to communicate and last but not least, they use it at conferences. In fact, there is growing body of research literature dealing with the use of Twitter for scientific purposes $[5,6]$. 
Although the features of Twitter are widely known, we will describe them briefly: Twitter allows registered users to share short posts of up to 140 characters to anybody else registered on Twitter. Such posts are called "tweets" and they can be seen as publicly accessible SMS. On $22^{\text {nd }}$ of February 2010 Twitter hit 50 millions tweets per day $^{1}$ and now surpassed 10 billion tweets altogether ${ }^{2}$. This overwhelming number of individual tweets evokes the need for the organization and selection of relevant tweets: Although Twitter was designed to be a one-way information sharing channel, community-driven approaches soon emerged to enhance the service with mark-ups that enabled more flexible communication within Twitter (see Java et al. [7]).

Therefore Twitter is equipped with a number of features:

(a) one can "follow" - that is, select the streams of interesting Twitter users;

(b) one can search for terms or tags (marked with "\#”; known as hashtags) used within tweets;

(c) one can directly address other users by a public reply (marked with “@” before the name of the other user; e.g. @ mebner) or via a private direct message (marked with "d" or "dm"; e.g. d wollepb);

(d) one can cite and copy interesting tweets by "retweeting" them (marked with "RT"; see Boyd et al. [8] for more information on retweeting messages in Twitter).

The growing success of Twitter has attracted the attention of other web services. Popular social networking platforms such as Facebook or LinkedIn allow the integration of tweets via a provided API and therefore make the application even more attractive. Twitter is not merely an additional communication channel; it appears that it has also been instrumental in changing the way people exchange information, links and their engagement with social media in general. The limited message size of 140 characters is often argued to be both strength and weakness of the microblogging service. In essence, the application offers fast, real-time and easy exchange but conversely, communication is mostly superficial, not sustainable over a long time period and rarely extends beyond single responses.

Twitter's initiating question "What are you doing?" to motivate people to talk about their private lives has already been advanced to "What is happening?" to encourage comments from those participating in events, especially within the context of media and e-learning. The special Twitter syntax (see (a) to (d)) suggests an obvious application for scientific conferences. In order to join a community's discussion about a topic or the participate within whole conference it is sufficient to tag one's messages with the official hashtag of the conference - a certain word following the number sign (\#) - or other existing tags. Without knowing other people at the conference, it is simple to aggregate their tweets. It becomes easier to share ideas, impressions, comments and additional materials about the conference on such a filtered \#channel. Furthermore, there is no setup required for the service - it is an online accessible application. Those who are interested in actively using Twitter need to be registered with the service and post their messages via the Twitter website or via one of the numerous clients using the provided API. Conference delegates and non-attendees can

\footnotetext{
${ }^{1} \mathrm{http}: / /$ mashable.com/2010/02/22/twitter-50-million-tweets/ (last visited April 2010).

${ }^{2} \mathrm{http} / / / \mathrm{mashable.com/2010/03/04/twitter-10-billion-tweets-2/} \mathrm{(last} \mathrm{visited} \mathrm{April} \mathrm{2010).}$
} 
search for tweets within the conference hashtag and are therefore able to follow the ongoing microblogging stream from the conference.

Twitter emerged as a conference communication tool firstly as a result of the experimentation of early adopters. Initially Twitter usage was officially unannounced or unsupported by conference organizations and therefore this communication use of Twitter could be described as essentially a hidden backchannel as Ebner explains in [9]. "Hidden" in this sense does not mean that it was not available for everyone, but that it had been undiscovered by the majority of participants. Ebner and Reinhardt show that at tech and media conferences in particular, the public announcement of a hashtag and a short explanation of Twitter as a conference backchannel eventually became a common feature [10].

In addition to this unofficial usage of Twitter at conferences, several other conceivably intentional scenarios that had already been used:

- $\quad$ Make the Twitter communication visible to all participants: To do so a public extra screen with a Twitter wall, listening to all current tweets was placed at the front of the conference hall beside the normal whiteboard. For example, a twitter wall was used at the ED-MEDIA conference 2008 [9]. Reinhardt et al. pointed out how people are using Twitter at conferences [11], showing that different stakeholders use Twitter before, during, and after a conference with differing purposes in mind. The analysis of the usage of the wall shows a surprisingly high participation of the conference attendees at the wall. Nevertheless, to the best to our knowledge, no content analysis about the communication and information flow at the wall was done.

- As for the presumption that a Twitter wall without concrete ideas about its functionality tends to distract the public and the presenters; the usage of the Twitter wall seemed to be too low-key or leads to be a non-constructive murmuring in the background as Danah Boyd experienced [12]. Therefore, conference organizers tried to build on the positive aspects of the tool to try to focus the communication. For example, there have been requests to use Twitter as an additional channel to ask questions during panel discussions (see Campus Innovation 2009 in Hamburg ${ }^{3}$ ). Additionally Ebner elaborates that presenters sometimes ask directly for feedback, open questions or comments via Twitter [9]. This is used to make presentations more interactive, especially in large audiences where a microphone would normally have been required for interaction between delegates and presenters.

- Besides traditional scientific conferences, barcamps attract researchers too, at least within the tech and media related disciplines. Barcamps are a kind of "unconference" [13] that function without prepared scheduled presentations and presenters to encourage more spontaneous, interactive communications and knowledge exchange in ad hoc installed stand-up presentations, workshops and discussion groups. Barcamps build upon the use of Web 2.0 technologies, open formats and tools. For example, they typically use wikis for registrations and social networking platforms to send out invitations and promote the event. Even more interestingly, the usage of Twitter seems more

\footnotetext{
${ }^{3}$ http://www.campus-innovation.de/node/580 (last visited April 2010).
} 
or less a matter of course for the participants. For example the announcement of workshops are typically amplified via Twitter; tweets are normally presented on screens in the lobby of the conference.

- Additionally, as Ebner and Reinhardt report, the conference organizers can actively use Twitter before and after the event: to promote the call for papers and event itself, to alert the full program, the registration possibilities, and afterwards the publication of the proceedings [10].

Nevertheless, these intended and "officially" announced and supported uses of Twitter at conferences are currently not widely used in every discipline and community of researchers. As Twitter is not limited to conference participants, it may encourage external participation. Additionally, Twitter is sometimes actively used to report conference activities to external participants.

To sum up, there are several clear ways Twitter can be used in the context of conferences:

(a) for communication amongst participants,

(b) for communication amongst organizers/presenters and audience,

(c) for reporting to non-participants about the conference.

Recent research work has focused mainly upon simple quantitative analysis, dealing questions such as how many tweets have been contributed from how many users in a specific time frame. This kind of measurement is used to gauge the success levels of Twitter use. In this publication we answer the main research question: "Is Twitter proper to report from a conference in order to share the event with the scientific community from outside the conference?" To do so we analyzed the Twitter stream of EduCamp 2010 in Hamburg, Germany.

\section{Study}

The Twitter API not only ensures there are numerous clients for sending and displaying tweets, but it also facilitates a systematic analysis of the content people publish on the platform. Reinhardt introduced an application that performed a basic analysis of tweets from communities of interest and visualized the main structural statistics about those communities, including a dynamic representation of the community's communication topics [14].

For this study we chose the EduCamp 2010 in Hamburg, because many participants are active Twitter users. Furthermore, the organization committee promoted the use of the microblogging platform by providing an appropriate hashtag (\#ec10hh) and actively encouraged exchange and communication via Twitter. As the EduCamp is organized as a "barcamp" or "un-conference", no scheduled program with concrete talks or workshops was available before it starts.

We monitored the output of the Twitter usage between the $5^{\text {th }}$ of February to the $4^{\text {th }}$ of March 2010. The EduCamp itself took place on $5^{\text {th }}$ and $6^{\text {th }}$ of February 2010. So in our study tweets from after the event are also counted and analyzed. In summary 2.110 single tweets containing the mentioned hashtag constitute the data in this study. We therefore examined twice - the core conference output as well as the post conference phase for about one month. Due to the fact that Twitter is used for communication 
issues post-event microblog postings are collected until appearances of the official hashtag begin to tail off.

Furthermore it must be noted that the 5 of 6 authors did not participate within the conference to ensure a neutral view to each single tweet.

Focusing on our main research question, we took a closer look at the content of each single tweet. Would a non-participant be able to follow the conference by watching the live-stream or would he/she simply become lost in information overload? Is the information provided on Twitter useful for the followers on the World Wide Web without them being physically present at the (un-)conference?

In this study a two-stage analysis was chosen - first an automatic one by analyzing main keywords, a so-called Formal Concept Analysis (FCA) (a detailed description follows later on). Secondly, tweets were analyzed manually and categorized into the following four categories, which we describe more precisely:

- irrelevant tweets,

- administrative tweets,

- topical discussions,

- topical tweets.

\section{Irrelevant Tweets}

This category contains all tweets that are not relevant to the topic of the conference. This means there is no hint towards learning, educational technology and so on. These tweets are comparable to usual small talk on conferences and the Web. Typical tweets in this category are the following:

- "Who found my drinking cup? \#ec10hh"

- "was online \#ec10hh"

\section{Administrative Tweets}

This category consists of all tweets with an administrative meaning. Examples of such content might be about the room in which a session is going to take place, or any technical information such as wireless LAN or hotspot issues, video/audio streaming issues etc. Typical tweets belonging to this category include the following:

- "Wifi is not available \#ec10hh"

- "Session: new music interfaces at 5:00 pm in room Durkheim \#ec10hh"

- "\#ec10hh streaming in room Humboldt not working?"

\section{Topical Discussions}

This category counts all tweets that are relevant in the context of learning and additionally are part of discussions on certain topics or replies to other participants. Typical tweets of this category are tweets include:

- “@mccab99 tell me about the relationship between technology and education? \#ec10hh"

- “nice idea of @estudyskills Aggregation of all student weblogs at Tumblelog - gives overview. \#ec10hh" 
- “dito! rt @lisarosa dance education: @mons7 shows, what we need: creativity + passion + engagement. \#ec10hh"

\section{Topical Tweets}

This category consists of all tweets relevant in the context of e-learning and that carry some valuable information with a strong focus on a conference topic. For example, in this category tweets consist of a little description and an additional link to another more detailed resource on the Web or simply describe / announce conference outcomes. Typical tweets of this category might be:

- "open-learning: initiative on OER usage for informal education: http://u.nu/4a7y4 \#ec10hh"

- "session on exploring teaching and learning. Make a look to this article of Gabi Reinmann: http://u.nu/3g8y4 \#ec10hh"

- "portal of TU Braunschweig integrates numerous services such as StudIP, library, plus community: http://bit.ly/atxvaR \#ec10hh"

The first two categories can be summed up in order to represent all the tweets of no relevance in the context of e-learning or to the discussed conference topics, while the latter two categories can be summed up as representative of the relevant tweets that might enhance the knowledge of external followers.

\section{Results}

\section{General Output}

Before analyzing each single tweet, a short overview about the participant sample and their tweets is given. Overall in the mentioned time period 272 users posted at least one single tweet using the hashtag \#ec10hh. Fig. 1 and Fig. 2 show that an average user posted about 8 posts and that there were some few users who contributed by using the application very extensively (one user posted 100 messages). At the other end of the spectrum, more than 108 users made just a single tweet. A detailed analysis showed that 272 users made an average of about 8 tweets (mean: 7.84; minimum: 1; maximum: 100; median: 3 ).

\section{Automated Analysis - Formal Concept Analysis (FCA)}

Our first approach uses Formal Concept Analysis (FCA) in order to categorize twitter users who write tweets about the same topics. A formal context is defined as set structure $K:=(\mathrm{G}, \mathrm{M}, \mathrm{I})$, where $\mathrm{G}$ represents objects (in German "Gegenstände"), M refers to attributes (in German "Merkmale") and I describes a binary relation between G and M. It can be represented as a matrix where rows contain objects and columns contain attributes. If there were a binary relation between a certain row and a certain column, this would be expressed by the identified cell having the value of 1 . If there is no relation the identified cell is assigned the value 0 .

A formal concept of a formal context $K:=(\mathrm{G}, \mathrm{M}, \mathrm{I})$ is defined as a pair (A, B) where $A$ is a subset of $G, B$ is a subset of $M\left(A=B^{\prime}\right.$ and $\left.B=A^{\prime}\right)$. A is called the 
extent and B is called the intent of the formal concept (A, B) [15]. The extent holds all objects belonging to a certain concept. The intent contains all attributes (e.g. properties, meanings) that apply to all those objects. As an entry point for further details on Formal Concept Analysis we refer to Wille and Ganter [15,16].

In this study we focus on categorizing different Twitter users depending on the tweets they wrote. The formal context $K:=(\mathrm{G}, \mathrm{M}, \mathrm{I})$ is defined as follows: All the keywords used within the tweets represent the attributes (M) and the users who wrote these tweets represent the objects $(\mathrm{G})$. A concept $(\mathrm{A}, \mathrm{B})$ is represented by a set $\mathrm{A}$ of keywords, which represents the intent and a set of twitter users (B) which represents the extent of this concept (e.g. all the Twitter users who used the keyword "e-learning" in their tweets).

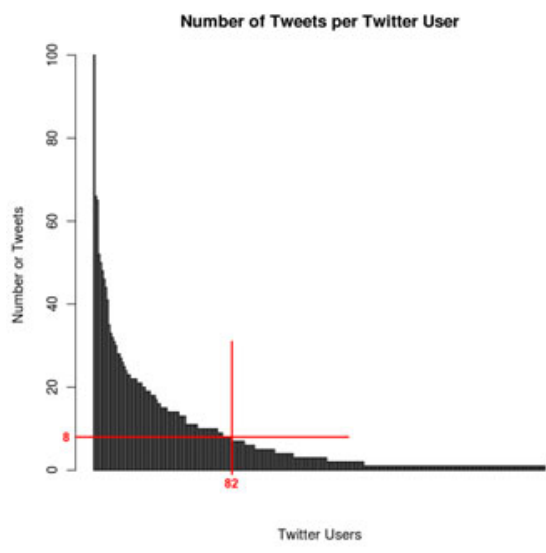

Fig. 1. Number of tweets per user

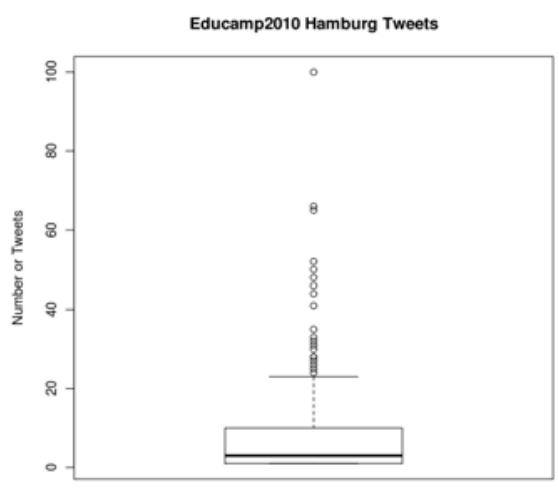

Fig. 2. Average of posts per user

In order to extract the keywords of the tweets we used the Yahoo Term Extraction Web Service ${ }^{4}$. The web service delivers a list of keywords for given tweets. For every Twitter user tweeting in the \#ec10hh Twitter stream the keywords were extracted and as a result a formal context was created. Analyzing the formal context was done with ConExp ${ }^{5}$. ConExp allows users to explore, analyze and visualize formal concepts of a formal context.

In order to focus only on the conference context irrelevant keywords were manually deactivated from relevant ones. The result was a sparse matrix that means that the extracted keywords did not overlap in a significant manner. It can be interpreted in such a way that monitored twitter users wrote about many different topics (e.g. using a lot of different keywords in their tweets). The categorization of twitter users based on their tweets using FCA did not result in valuable categories. It can be stated that the tweets analyzed have high diversity and nearly no overlapping keywords. The result is that the tweets are required to be manually analyzed.

\footnotetext{
${ }^{4} \mathrm{http}: / /$ developer.yahoo.com/search/content/V1/termExtraction.html (last visited April 2010).

${ }^{5} \mathrm{http}: / /$ conexp.sourceforge.net/ (last visited April 2010).
} 


\section{Manual Analysis}

In total $57 \%$ of 2.110 analyzed tweets could generally be categorized as irrelevant in the context of the (un-) conference outcome. As illustrated in Table 1, 13\% of the tweets were categorized as administrative tweets, $9 \%$ were marked as discussions and $20 \%$ were categorized as relevant tweets.

Table 1. Categorization of tweets

\begin{tabular}{cccccc}
\hline & $\begin{array}{c}\text { Topical } \\
\text { Tweets }\end{array}$ & $\begin{array}{c}\text { Topical } \\
\text { Discussions }\end{array}$ & $\begin{array}{c}\text { Administrative } \\
\text { Tweets }\end{array}$ & $\begin{array}{c}\text { Irrelevant } \\
\text { Tweets }\end{array}$ & $\begin{array}{c}\text { Total } \\
\text { Number } \\
\text { of Tweets }\end{array}$ \\
\hline $\begin{array}{c}\text { Number of Tweets } \\
\text { including Retweets }\end{array}$ & 456 & 201 & 278 & 1.175 & 2.110 \\
\hline $\begin{array}{c}\text { Number of Tweets } \\
\text { not containing "RT } \\
\text { @" or "via @" - } \\
\text { Clean Tweets }\end{array}$ & 346 & $10 \%$ & $13 \%$ & $56 \%$ & $100 \%$ \\
\hline & $\mathbf{2 0 \%}$ & $\mathbf{9 \%}$ & 227 & 996 & 1.726 \\
\hline
\end{tabular}

In the following section we offer a more detailed analysis of the categories relevant tweets and relevant discussions. Table 2 displays all categorized tweets over the monitored time period. Furthermore, the table also highlights all tweets sent during the conference time (February $5^{\text {th }}$ to February $6^{\text {th }} 2010$ ) in parentheses.

Table 2. Detailed analysis of Tweets

\begin{tabular}{|c|c|c|c|c|c|}
\hline & $\begin{array}{l}\text { Topical } \\
\text { Tweets }\end{array}$ & $\begin{array}{c}\text { Topical } \\
\text { Discussions }\end{array}$ & $\begin{array}{l}\text { Administrative } \\
\text { Tweets }\end{array}$ & $\begin{array}{l}\text { Irrelevant } \\
\text { Tweets }\end{array}$ & $\begin{array}{c}\text { Total Number } \\
\text { of Tweets }\end{array}$ \\
\hline $\begin{array}{c}\text { Number of } \\
\text { Tweets } \\
\text { including } \\
\text { Retweets } \\
\end{array}$ & $\begin{array}{c}456 \\
(349)\end{array}$ & $\begin{array}{c}201 \\
(162)\end{array}$ & $\begin{array}{c}278 \\
(193)\end{array}$ & $\begin{array}{l}1.175 \\
(939)\end{array}$ & $\begin{array}{c}2.110 \\
(1.643)\end{array}$ \\
\hline $\begin{array}{c}\text { Number of } \\
\text { Tweets } \\
\text { containing at } \\
\text { least one link }\end{array}$ & $\begin{array}{c}249 \\
(164)\end{array}$ & $\begin{array}{c}37 \\
(19)\end{array}$ & $\begin{array}{l}123 \\
(85)\end{array}$ & $\begin{array}{c}207 \\
(138)\end{array}$ & $\begin{array}{c}616 \\
(406)\end{array}$ \\
\hline $\begin{array}{c}\text { Number of } \\
\text { Replies }\end{array}$ & $\begin{array}{c}40 \\
(32)\end{array}$ & $\begin{array}{c}70 \\
(61)\end{array}$ & $\begin{array}{c}34 \\
(26) \\
\end{array}$ & $\begin{array}{c}228 \\
(179)\end{array}$ & $\begin{array}{c}372 \\
(298)\end{array}$ \\
\hline $\begin{array}{l}\text { Number of } \\
\text { Tweets } \\
\text { containing } \\
\text { "RT @" }\end{array}$ & $\begin{array}{l}101 \\
(72)\end{array}$ & $\begin{array}{c}42 \\
(33)\end{array}$ & $\begin{array}{c}50 \\
(34)\end{array}$ & $\begin{array}{c}172 \\
(131)\end{array}$ & $\begin{array}{l}365 \\
(270)\end{array}$ \\
\hline $\begin{array}{c}\text { Number of } \\
\text { Tweets contain- } \\
\text { ing "via @" }\end{array}$ & $\begin{array}{l}10 \\
(7)\end{array}$ & $\begin{array}{c}2 \\
(2)\end{array}$ & $\begin{array}{c}1 \\
(1)\end{array}$ & $\begin{array}{c}8 \\
(8)\end{array}$ & $\begin{array}{c}21 \\
(18)\end{array}$ \\
\hline
\end{tabular}


Table 2. (Continued)

\begin{tabular}{|c|c|c|c|c|c|}
\hline & $\begin{array}{l}\text { Topical } \\
\text { Tweets }\end{array}$ & $\begin{array}{c}\text { Topical } \\
\text { Discussions }\end{array}$ & $\begin{array}{l}\text { Administrative } \\
\text { Tweets }\end{array}$ & Irrelevant Tweets & $\begin{array}{l}\text { Total Number } \\
\text { of Tweets }\end{array}$ \\
\hline $\begin{array}{l}\text { Number of } \\
\text { Tweets } \\
\text { containing } \\
\text { "RT @" and } \\
\text { containing } \\
\text { "via@" }\end{array}$ & $\begin{array}{c}1 \\
(1)\end{array}$ & $\begin{array}{c}0 \\
(0)\end{array}$ & $\begin{array}{c}0 \\
(0)\end{array}$ & $\begin{array}{c}1 \\
(1)\end{array}$ & $\begin{array}{c}2 \\
(2)\end{array}$ \\
\hline $\begin{array}{l}\text { Number of } \\
\text { Tweets } \\
\text { containing } \\
\text { "RT @" or } \\
\text { containing } \\
\text { "via @" but } \\
\text { not both }\end{array}$ & $\begin{array}{l}110 \\
(78)\end{array}$ & $\begin{array}{c}44 \\
(35)\end{array}$ & $\begin{array}{c}51 \\
(35)\end{array}$ & $\begin{array}{c}179 \\
(138)\end{array}$ & $\begin{array}{c}384 \\
(286)\end{array}$ \\
\hline $\begin{array}{c}\text { Number of } \\
\text { Tweets not } \\
\text { containing } \\
\text { "RT @" or } \\
\text { "via @" - Clean } \\
\text { Tweets }\end{array}$ & $\begin{array}{c}346 \\
(271)\end{array}$ & $\begin{array}{c}157 \\
(127)\end{array}$ & $\begin{array}{c}227 \\
(158)\end{array}$ & $\begin{array}{c}996 \\
(801)\end{array}$ & $\begin{array}{c}1.726 \\
(1.357)\end{array}$ \\
\hline $\begin{array}{c}\text { Number of } \\
\text { Tweets not } \\
\text { containing "RT } \\
\text { @" or "via @" } \\
\text { and containing } \\
\text { at least one link }\end{array}$ & $\begin{array}{c}175 \\
(120)\end{array}$ & $\begin{array}{c}28 \\
(15)\end{array}$ & $\begin{array}{c}84 \\
(57)\end{array}$ & $\begin{array}{c}148 \\
(102)\end{array}$ & $\begin{array}{c}435 \\
(294)\end{array}$ \\
\hline
\end{tabular}

\section{Discussion}

In the analysis of categories of interest the following crucial facts should be highlighted:

- In the timeslot of the conference (5th to 6th February 2010) 1.643 tweets from 2.110 were tweeted by 272 users in total. It can thus be stated that on average each user posted an average 6 tweets during the conference period.

- During the analysis it was also attempted to separate participating active Twitter user from non-participating ones, but because many use their accounts anonymously more than 100 users could not be identified.

- Monitoring the conference: For a non-participant of a conference who wishes to monitor the event by checking the Twitter live stream this proves to be problematic. Based on the assumption that even relevant tweets containing simple statements are senseless without any distinct context of the occurrence, only messages containing additional material (such as pictures, videos, or similar) may be of interest. In other words, if a link to such an attachment occurs, it might be possible to understand the current conference situation. Only 175 out of 2.110 tweets offered such a possibility. $8 \%$ or only one out of twelve is maybe of interest. To follow the conference stream seems to be a challenge. If we reduce the tweets to those occurring during the conference 
period (5th and 6th February) (Table 2) only 120 posts are of interest at all, which relates to about $6 \%$.

- Retweets: Table 2 shows the high number of retweets (RT) in conference twittering. In summary $384 \mathrm{RTs}$ occurred which is an overall percentage of $18 \%$, but if the "relevant" category is analyzed towards RTs we see that $24 \%$ of all tweets are simply a copy of previous ones. On one hand the retweet seems to be a relevant message, otherwise it would not been multiplied by another user. But, on the other hand, it may hold no sense for people who are not at this conference because they need the context of the proposed tweet to understand the content.

- Bearing in mind that RTs are a good instrument for pointing out the importance of a tweet or helping to reach more Twitter user in order to spread the world with announcements, they are not helpful if someone is interested on the content/output of the conference.

- Subsequent to the keyword extraction and calculation, the FCA revealed that there is no direct correlation amongst the conference participants. In other words, with this method it was not possible to gain an overview about the conference topics, the main assumptions or statements.

\section{Conclusion}

Our analysis showed that the use of Twitter to distribute or explain (un-) conference topics, discussions or results to a broader public seems to be limited.

To interpret the data correctly, further comparative data and analysis are required. Our approach of analyzing tweets at a conference was merely the first foray into what has become a complex research field.

Our analysis demonstrated that the Twitter stream has a limited usefulness at his particular conference for external participants that wanted to follow the event from outside, and we conclude that our own ideas and implicit theories about the Twitter usage should be perhaps be reassessed. In this paper the content of tweets was analyzed for the first time and a first trend was carried out to give an overview of Twitter usage. As has been previously mentioned, further examination will be necessary to confirm these outcomes, even though Ross et al. [17] reports similar results: "[The analyzed data] raises the question of whether a Twitter enabled backchannel promotes more of an opportunity for users to establish an online presence and enhance their digital identity rather than encouraging a participatory conference culture."

Possible interpretations of the results could be that the Twitter usage follows other logic, e.g.:

- usage as a backchannel for conference participants or even a subgroup at the conference as a means to comment silently with limited comprehension potential for outsiders;

- usage of self promotion and profiling that means for example citations of people at the conference with a possible high retweet rate are posted to generate attention for the own profile;

- to document and illustrate connections, for example friendship, acquaintanceship, social ties to others ("I know ... and like her/his idea") in the same way as making new connections and friendship; 
- $\quad$ usage as a public notepad to collect relevant ideas, quotes or links;

- usage as an evaluation tool, for example to collect quotes about the conference and the satisfaction of participants for use by the organizing committee.

Further research activities should combine the quantitative, semi-automatic analysis as we have achieved within this contribution with additional questioning and involvement about the aims and goals of the Twitter user at a conference. One weakness of the presented data is that there is no determining if a RT was sent by a conference participant or by external participants. The authors attempted to categorize each Twitter user but because of missing data this should be done beforehand in future studies.

Nevertheless, Twitter is a "new" tool and therefore adaptations of new forms of communications, e.g. etiquette for documentation of conference for outsiders or a more focused usage of tweets by the presenters or conference organizers could positively influence future usage.

Practically, the obviously limited usefulness of the tweets of the EduCamp participants for interested external participants evokes new ideas for practical and effective alternative usage of the tweets as well as the need for appropriate tools. For example, an individual's micro postings might be seen as personal notes, as they are obviously easier interpreted and meaningful for the writers themselves. Therefore, future tools could develop and support the self-archiving functionalities of Twitter (e.g. search functions about the own tags).

Acknowledgments. The authors would like to thank Michael Rowe and Alexandre Passant for their comprehensive, valuable reviews of an earlier version of this paper.

\section{References}

1. Ebner, M., Schiefner, M.: Microblogging - more than fun? In: Proceedings of IADIS Mobile Learning Conference, Portugal, pp. 155-159 (2008)

2. Ebner, M., Lienhardt, C., Rohs, M., Meyer, I.: Microblogs in higher education - a chance to facilitate informal and process oriented learning? Computers \& Education 55(1), 92-100 (2010)

3. Costa, C., Beham, G., Reinhardt, W., Sillaots, M.: Microblogging in Technology Enhanced Learning: A Use-Case Inspection of PPE Summer School 2008. In: Proceedings of the 2nd SIRTEL Workshop on Social Information Retrieval for Technology Enhanced Learning (2008)

4. Grosseck, G., Holotescu, C.: Can we use twitter for educational activities? In: Proceedings of the 4th International Scientific Conference eLSE "eLearning and Software for Education" (2008)

5. Letierce, J., Passant, A., Decker, S., Breslin, J.: Understanding how Twitter is used to spread scientific messages. In: Web Science Conference, Raleigh, NC, USA (2010), http: / / journal.webscience.org/314/ (last visited April 2010)

6. Haewoon, K., Changhyun, L., Hosung, P., Moon, S.: What is Twitter a Social Network or a News Media? In: Proceedings of the 19th International World Wide Web (WWW) Conference, Raleigh, NC (USA), April 26-30 (2010), http://an.kaist.ac.kr/ traces /WWW2 010. html (last visited April 2010) 
7. Java, A., Song, X., Finin, T., Tseng, B.: Why we twitter: understanding microblogging usage and communities. In: Proceedings of the 9th WebKDD and 1st SNA-KDD 2007 Workshop on Web Mining and Social Network Analysis, pp. 56-65. ACM, New York (2007)

8. boyd, d., Golder, S., Lotan, G.: Tweet, tweet, retweet: Conversational aspects of retweeting on twitter. In: Proceedings of the HICSS-43 Conference (2010)

9. Ebner, M.: Introducing Live Microblogging: How Single Presentations Can Be Enhanced by the Mass. Journal of Research in Innovative Teaching (JRIT) 2(1), 91-100 (2009)

10. Ebner, M., Reinhardt, W.: Social networking in scientific conferences - Twitter as tool for strengthen a scientific community. In: Proceedings of the 1st International Workshop on Science 2.0 for TEL (2009)

11. Reinhardt, W., Ebner, M., Beham, G., Costa, C.: How people are using Twitter during Conferences. In: Hornung-Prähauser, V., Luckmann, M. (eds.) Creativity and Innovation Competencies on the Web. Proceedings of the 5th EduMedia 2009, Salzburg, pp. 145-156 (2009)

12. boyd, d.: Spectacle of Web 2.0 Expo ... from my perspective (2009), http://www. zephoria.org/thoughts/archives/2009/11/24/spectac le_at_we.html (last visited April 2010)

13. Bernhardt, T., Kirchner, M.: Web 2.0 meets conference - the EduCamp as a new format of participation and exchange in the world of education. In: Ebner, M., Schiefner, M. (eds.) Looking Toward the Future of Technology-Enhanced Education: Ubiquitous Learning and the Digital Native, pp. 192-204. IGI Global, Hershey (2010)

14. Reinhardt, W.: Visualizing the dynamics of communication of Communities of Practice on Twitter. In: Proceedings of the 3rd International Workshop on Building Technology Enhanced Learning solutions for Communities of Practice (2009)

15. Wille, R.: Formal Concept Analysis as Mathematical Theory of Concepts and Concept Hierarchies. In: Ganter, B., Stumme, G., Wille, R. (eds.) Formal Concept Analysis. LNCS (LNAI), vol. 3626, pp. 1-33. Springer, Heidelberg (2005)

16. Ganter, B., Wille, R.: Formal concept analysis: Mathematical foundations. Springer, Heidelberg (1999)

17. Ross, C., Terras, M., Warwick, C., Welsh, A.: Enabled Backchannel: Conference Twitter Use by Digital Humanists, Department of Information Studies, draft version (2009), http://www.ucl.ac.uk/infostudies/claire-ross/Digitally _Enabled_Backchannel.pdf (last visited April 2010) 